\title{
Strategic Research on the Urban Natural Gas Energy System Under the Path to Ecological Civilization: Fuyang City Case Study
}

\author{
Yun-li Hao ${ }^{1,2}$, Shuang $\mathrm{Li}^{1 *}$ and Qing Xia ${ }^{1}$ \\ ${ }^{1}$ School of Management, China University of Mining and Technology, Xuzhou, China, ${ }^{2}$ Department of Mathematics, College \\ of Information Engineering, Fuyang Normal University, Fuyang, China
}

OPEN ACCESS

Edited by:

Xunpeng Roc Shi,

University of Technology

Sydney, Australia

Reviewed by:

Qunwei Wang,

Nanjing University of Aeronautics and

Astronautics, China

Ren Fangrong,

Hohai University, China

${ }^{*}$ Correspondence:

Shuang Li

lishuangchina@cumt.edu.cn

Specialty section:

This article was submitted to Sustainable Energy Systems and

Policies,

a section of the journal Frontiers in Energy Research

Received: 21 August 2019 Accepted: 29 November 2019 Published: 10 January 2020

Citation:

Hao Y, Li S and Xia Q (2020) Strategic

Research on the Urban Natural Gas

Energy System Under the Path to

Ecological Civilization: Fuyang City

Case Study. Front. Energy Res. 7:147.

doi: 10.3389/fenrg.2019.00147
To help meet the strategic development needs of urban energy systems today and reduce carbon emissions, natural gas can play a pivotal transition role, especially in a country such as China, which has relied very heavily on coal for decades. Though making significant progress toward the maximum possible use of clean, renewable forms of energy, such as hydro, thermal, solar, and wind power, it will take a long time before China can completely abandon the use of fossil fuels. In this paper, using Fuyang City in Anhui Province as a case study, a four-dimensional differential equation model, based on the consumption, price, economic growth, and "ecological civilization construction" of natural gas energy, is developed, which incorporates concepts and calculations of natural gas energy intensity, "natural gas ecological civilization intensity," and "economic ecological civilization intensity." It is the first attempt ever made to quantify the construction of urban ecological civilization and discuss the evolutionary relationship among the internal variables of the system. Regression analysis, data fitting, neural network, and other methods are used to confirm the parameters of the system model. Through Matlab simulation of each variable and using an evolution map, a quantitative understanding of the role of natural gas is generated. The research findings reveal that paying attention to the environmental aspects of energy consumption is beneficial to economic growth. The paper concludes that, at present, the best ways for China to reduce its carbon emissions are to implement a market price and peak-valley prices for natural gas, improve the tiered price mechanism, appropriately reduce the economic growth rate, continue to adjust the industrial structure away from heavy industry, and scientifically manage the natural gas energy system. These reforms are of great practical significance in working toward a sustainable development path for the city.

Keywords: natural gas, differential equation, natural gas energy intensity, natural gas ecological civilization intensity, economic ecological civilization intensity

\section{INTRODUCTION}

After more than 30 years of rapid economic development, China has created considerable material wealth. However, the country's enormous resource consumption has resulted in severe pollution of the atmosphere, soil, and water, leading to increasingly serious ecological problems. There is an urgent need to protect the ecological environment, by greatly reducing environmental pollution, 
strengthening the importance of "ecological civilization construction" (described below), and creating a good working and living environment for the people (Zhang et al., 2018).

In 1978, the reform and opening up of China established "economic construction" as the central task of the whole nation. However, economic development led to rapid deterioration of the ecological environment. Therefore, in 1983, the central government established environmental protection as a fundamental national policy for China and enacted many relevant laws (Wang and Gao, 2017). With the introduction of the concept of "sustainable development" by the United Nations, the Central Committee of the Communist Party of China (CPC) proposed a sustainable development strategy. Under the guidance of the "scientific concept of development," the 16th National Congress of the CPC formed the strategic concept called "building an ecological civilization" (Du, 2015). The report of the 17th National Congress of the CPC provides a clear definition and explains the connotations of ecological civilization, and lists "constructing ecological civilization" as the new requirement for building a well-off society in a comprehensive manner (Zeng and Liang, 2018). The Third Plenary Session of the 18th CPC Central Committee pointed out that: "To build an ecological civilization, we must establish a systematic and complete ecological civilization system, and use this system to protect the ecological environment. Use natural resource assets to determine the red line of ecological protection. Use system and ecological compensation system [to reform] the ecological environmental protection management system." In addition, at the Fifth Plenary Session of the 18th CPC Central Committee, "Green Development" was promoted to become one of the "five major development" concepts. "Beautiful China" was first written into the 13th Five-Year Plan, and the construction of ecological civilization was ranked as an even higher priority than it had been before (Xiao, 2008). At the 19th National Congress of the CPC, the Party proposed a comprehensive plan for the construction of ecological civilization ( $Y u, 2018$ ), put forward the concept of "the harmonious coexistence of man and nature," and proposed a new development direction, the road to sustainable development (Jiang et al., 2019).

In recent years, China has made remarkable achievements in resource conservation and effective resource use, but there is still a large gap between China and the world's advanced countries (Hansen et al., 2018). China must incorporate ecological science in its development instead of endlessly pursuing blind growth. It must vigorously implement green environmental protection work, promote sustainable development, establish awareness of the green economy, and ensure a healthy lifestyle for its inhabitants (Xie et al., 2019). Other countries have also adopted the concept of "construction of ecological civilization" and are likewise striving for the same goals (Zhu, 2016; Zhang and Yang, 2019).

Fuyang City is a third-tier city (according to the size of the city, population, level of economic development, and the total economic value) situated in China's Anhui Province, with a population density of 850 people per square kilometer and a total population of over 10 million, comparable to that of the nation's capital, Beijing. In recent years, the economy has grown at an average rate of $9.5 \%$, with gross domestic product (GDP) reaching 170 billion yuan in 2018, making Fuyang one of the wealthiest of China's third-tier cities. However, there is a shortage of energy and there are few coal resources nearby. Thus, Fuyang depends on the surrounding cities for electricity and energy sources. With the expansion of the city, the demand for natural gas has been increasing. Fortunately, the natural gas input channels are abundant and excellent. In recent years, the government of Fuyang City has placed great importance on the construction of ecological civilization. It has formulated plans and implementation measures focusing on the prevention of atmospheric, water, and soil pollution, hiring environmental protection inspectors to provide feedback, and ensuring that the environmental issues are rectified as quickly as possible. The central goals are to increase accountability in the field of ecological environmental protection, improve the long-term supervision mechanisms, and continue promoting awareness about environmental protection.

As the world's largest emitter of $\mathrm{CO}_{2}$, China faces an enormous challenge in reducing these emissions quickly. Natural gas is a high-heat energy source that emits far less $\mathrm{CO}_{2}$ than coal (or fuel oil). Generating electricity from natural gas does not completely eliminate $\mathrm{CO}_{2}$ emissions (Zhou et al., 2018). However, expanding its use across the country will help meet the growing demand for energy and also improve the current energy consumption structure (Xu and Lin, 2019). While many advanced countries abandoned the use of coal and fuel oil decades ago, in favor of natural gas, China is now adopting this "transition" fuel as rapidly as it can while concomitantly developing the various forms of renewable energy it has available, such as hydro, thermal, solar, and wind power, to the greatest extent possible. Indeed, given that China has a large and increasing population, and that the economic growth rate is relatively high, it has become a very urgent task to develop the natural gas industry in order to protect the fragile the ecological environment and strive for a more sustainable path toward modernization development (Tanaka, 2015; Wang et al., 2018).

Urban energy consumption accounts for two thirds of the total global energy consumption, and carbon emissions mainly come from cities. Yet, urban development connotes modern social progress (van Ruijven and van Vuuren, 2009; Emma and John, 2013). By 2030, it is predicted that $76 \%$ of the world's $\mathrm{CO}_{2}$ emissions from energy consumption will come from cities (Ji et al., 2014). China is at the stage of industrialization and urbanization in which emissions and the urban evaporation rate are expected to rise significantly higher until they finally peak. One-time energy consumption will continue to grow rapidly and place tremendous pressure on China's energy supply capacity and environmental protection policies. Though still not a completely clean form of energy, natural gas is an available, easily usable, and economical energy alternative with which to generate a large share of the huge amounts of electricity that the country requires, and is thus pivotal in China's goal to achieve the construction of a comprehensive ecological civilization (He and Lin, 2017; Mark et al., 2017; Liu et al., 2018; Li et al., 2019).

To date, there have been many qualitative studies on natural gas consumption, but few quantitative studies in China. Based 
on the logistic theory of energy consumption, Tian Lixin, Fang Guochang et al. (Fang et al., 2012, 2017, 2018a; Wang et al., 2015; Zhang and Tian, 2016) established a differential equation model for quantitative analysis of energy systems using chaos theory. Differential equations have great advantages in dealing with non-linear problems in many respects. Many studies have been conducted pertaining to energy conservation and emission reductions. This paper uses the differential equation method to establish a model to study the natural gas energy system of Fuyang City (Fang et al., 2013; Hao et al., 2019). In the past, Fuyang was a poor and densely populated city, with a backward economy, energy shortages, and a deteriorating environment. In recent years, however, it has ranked second and third in terms of economic growth and economic aggregate, respectively, in Anhui province (Hao et al., 2019), and ranked in the top 10 of third-tier cities in China. Over the past decade, it has invested significant funding toward sustainable development.

To purify the environment and create an ecological and modern city, the government of Fuyang in 2000 year issued a directive prohibiting the use of coal, upon which it has always relied almost entirely throughout its history. Arguably the most viable solution to its immediate energy and pollution problems is to raise the proportion of natural gas in its energy mix as rapidly as possible while also harnessing as much solar power as practical in the local conditions.

In this paper, the concept of "urban ecological civilization construction" is integrated into a mathematical model for the first time, and natural gas energy intensity, as well as the concepts of natural gas ecological civilization intensity and economic ecological civilization intensity are proposed. Studying an urban natural gas energy system under a path to ecological civilization can assist the government in formulating the most appropriate policies to improve the efficiency of energy utilization, quantify the construction of ecological civilization, strengthen the reform of the natural gas market, and enhance the development of tertiary industries. This study simulates and analyzes the market administrative measures that are most beneficial in achieving a more sustainable development strategy for the city. Its results are applicable not only to Fuyang, but also to many other cities in China.

\section{ESTABLISHMENT OF URBAN NATURAL GAS ENERGY MODEL}

The consumption of natural gas is influenced by the environment, government policies, and its price (Fang et al., 2018b; Ji et al., 2018). Existing research indicates that its consumption and price, along with economic growth (mainly measured in terms of GDP) form a complex system consisting of many elements (Ji and Zhang, 2018; Cheng et al., 2019), and that the relationships among these elements are nonlinear and complex in nature (Fang et al., 2012, 2017, 2018b; Wang et al., 2015). Exploring these relationships can assist the government of Fuyang City in its quest to reduce the pollution in and around the city.
Using a logistic model of energy consumption (Shi and Sun, 2017; Shia and Shi, 2019) as a basis, the specific models for urban natural gas consumption, natural gas prices, and economic growth are formulated as follows:

$$
\left\{\begin{array}{l}
\frac{d x}{d t}=a_{1} x(M-x)+a_{2}\left(1-\frac{y}{N}\right) x-a_{3} y+a_{4} z \\
\frac{d y}{d t}=b_{1} x+b_{2} y\left(1-\frac{y}{L}\right)+b_{3}(z-K) \\
\frac{d z}{d t}=c_{1} x\left(\frac{x}{Q}-1\right)-c_{2} z
\end{array}\right.
$$

where $x(t)$ represents natural gas consumption over time; $y(t)$ represents gas prices over time; $z(t)$ represents economic growth over time, and GDP. $a_{1}, a_{2}, a_{3}, a_{4}, b_{1}, b_{2}, b_{3}, c_{1}, c_{2}, M, N, L$, $k$, and $Q$ are the normal numbers. $t \in I, I$ is an economic period. The term $a_{1}$ is the development coefficient of natural gas consumption; $a_{2}$ is the influence coefficient of the price on the natural gas consumption; $a_{3}$ is the inhibition coefficient of the price on the natural gas consumption; $a_{4}$ is the development coefficient of economic growth on the natural gas consumption; $b_{1}$ is the development coefficient of natural gas consumption on the price; $b_{2}$ is the intrinsic growth coefficient of the natural gas price; $b_{3}$ is the influence coefficient of economic growth on the natural gas price; $c_{1}$ is the influence of natural gas consumption on economic growth; $c_{2}$ is the inhibition factor of natural gas investment, technology, and research and development on the economy; $M$ is the peak value of natural gas consumption in a city in an economic period; $N$ is the threshold value of the urban natural gas price in relation to natural gas consumption; $L$ is the peak value of the urban natural gas price; $k$ is the peak value of urban economic growth; and $Q$ is a turning point for natural gas consumption in relation to economic growth.

The first formula in Equation (1) states that, over time, the demand for natural gas as a share of urban energy sources increases gradually until it reaches the peak value of $M$, when it gradually slows; namely, at $M-x>0$, the demand for natural gas increases, whereas following this, the demand for natural gas slows down. When the price is below the threshold of $N$, that is, $1-y / N>0$, the price stimulates the consumption of natural gas. When $1-y / N<0$, the price exceeds this threshold, and it has an inhibitory effect on the consumption of natural gas. The term $a_{3} y$ indicates that natural gas consumption is inversely proportional to the natural gas price in the market. Hence, economic development results in increased consumption of natural gas.

The second formula in Equation (1) indicates that the consumption of natural gas has a positive effect on the price. The term $b_{2} y(1-y / L)$ indicates that many factors can impact the price of natural gas, such as geographical restrictions, the prices of electricity and oil, the peak and valley periods of gas demand, and the economic development of the city. When the natural gas price does not exceed the threshold $L$, which is determined by these factors, then the natural gas price can continue to increase. In contrast, when the price exceeds the threshold, the natural gas price will decrease. The term $b_{3}(z-k)$ indicates that economic development will increase the consumption of natural gas. When the growth rate of the economy is low, i.e., $z-k<0$, the 
market demand for natural gas is low, which means that natural gas prices remain low. However, when the growth rate of the economy has reached a certain point, i.e., $z-k>0$, the demand for natural gas energy, and thus prices, will both increase.

In the third formula in Equation (1), $c_{1} x(x / Q-1)$ refers to the natural gas consumption. During the early stages of development, namely, at $x / Q-1<0$, the cost of natural gas consumption is high because the natural gas management system is not well-developed. There are also limitations arising from the immature technical conditions in the early stages of natural gas exploration. At this time, the effect of natural gas consumption on economic growth is limited, which is a negative growth state. When the consumption of natural gas is more than $Q$, namely, when $x / Q-1>0$, it will have positive effects on economic development. The term $c_{2} z$ indicates that the development of natural gas will involve economic costs due to the development costs, technical research, transportation, and other factors.

\section{ESTABLISHMENT OF AN ENERGY SYSTEM MODEL OF ECOLOGICAL CIVILIZATION}

After adding the variable of ecological civilization to model (1) of the urban natural gas energy system, the new model is as follows:

$$
\left\{\begin{array}{l}
\frac{d x}{d t}=a_{1} x(M-x)+a_{2}\left(1-\frac{y}{N}\right) x-a_{3} y+a_{4} z+a_{5} w \\
\frac{d y}{d t}=b_{1} x+b_{2} y\left(1-\frac{y}{L}\right)+b_{3}(z-K) \\
\frac{d z}{d t}=c_{1} x\left(\frac{x}{Q}-1\right)-c_{2} z+c_{3} w \\
\frac{d w}{d t}=k_{1} x+k_{2} w\left(1-\frac{z}{H}\right)
\end{array}\right.
$$

Here, $w(t)$ represents the amount of ecological civilization, $a_{5}$ is the development coefficient of urban ecological civilization on natural gas energy, $c_{3}$ is the influence coefficient of ecological civilization construction on economic growth, $k_{1}$ is the development coefficient of natural gas consumption on ecological civilization construction, $k_{2}$ is the influence coefficient of economic development on ecological civilization, and $H$ is the peak value of economic development on ecological civilization construction.

Equation (2) in the fourth formula states that the use of the various forms of clean energy and natural gas has a significant positive effect on the construction of ecological civilization. $(1-z / H)<0$ indicates that excessive levels of economic inputs hinder the development of ecological civilization, whereas $(1-z / H)>0$ indicates that appropriate economic inputs have positive effects on ecological civilization.

The energy consumption system reflects the interdependence among natural gas consumption, the natural gas price, and economic growth in a certain economic period. The power system represented by Formula (1) can derive the following energy consumption of natural gas in a given period of time:

$$
\phi_{1}(x, y, z, w, R, t)=\int_{0}^{T} x^{*}(t) d t, x^{*}(t)=\varphi(x, t)
$$

Economic growth during this period can be expressed as follows:

$$
\phi_{2}(x, y, z, w, S, t)=\int_{0}^{T} z(t) d t
$$

The construction of ecological civilization in this period is as follows:

$$
\phi_{3}(x, y, z, w, V, t)=\int_{0}^{T} w(t) d t
$$

When $T$ is a given period, $R, S$, and $V$ are constants. Thus, the energy intensity of natural gas can be expressed as:

$$
U_{1}=\phi_{1}(x, y, z, w, R, t) / \phi_{2}(x, y, z, w, S, t)
$$

The intensity of natural gas energy ecological civilization is as follows:

$$
U_{2}=\phi_{1}(x, y, z, w, R, t) / \phi_{3}(x, y, z, w, V, t)
$$

TABLE 1 | Overview of the natural gas system in Fuyang City from 2007 to 2016.

\begin{tabular}{cccc}
\hline Year & $\begin{array}{c}\text { Natural gas consumption } \\
\text { (thousands of cubic meters) }\end{array}$ & $\begin{array}{c}\text { Pipe length } \\
\mathbf{( k m )}\end{array}$ & $\begin{array}{c}\text { Gas population } \\
\text { (thousands) }\end{array}$ \\
\hline 2007 & 626 & 200 & 4.2 \\
2008 & 2764 & 265 & 21.5 \\
2009 & 4870 & 380 & 23.95 \\
2010 & 6460 & 425 & 37.26 \\
2011 & 7300 & 458.1 & 45.5 \\
2012 & 8700 & 483 & 46.08 \\
2013 & 9260 & 502 & 48.68 \\
2014 & 6938 & 585 & 49 \\
2015 & 7040 & 585.4 & 49.5 \\
2016 & 10405 & 637.4 & 54.5 \\
\end{tabular}

TABLE 2 | Regression analysis of $a$ and $r$ in Fuyang City for the next 10 years.

\begin{tabular}{lccc}
\hline $\boldsymbol{K}(\mathbf{1 0 , 0 0 0}$ cubic meters) & $\boldsymbol{R}^{\mathbf{2}}$ & $\boldsymbol{a}$ & $\boldsymbol{r}$ \\
\hline 10,500 & 0.6974 & 2.2546 & 0.5376 \\
11,000 & 0.7104 & 1.9832 & 0.4311 \\
12,000 & 0.6927 & 1.9524 & 0.3702 \\
13,000 & 0.6785 & 1.9981 & 0.3402 \\
14,000 & 0.6677 & 2.0591 & 0.3209 \\
15,000 & 0.6591 & 2.1232 & 0.3071 \\
16,000 & 0.6523 & 2.1867 & 0.2966 \\
17,000 & 0.6466 & 2.2482 & 0.2883 \\
18,000 & 0.6418 & 2.3071 & 0.2815 \\
19,000 & 0.6377 & 2.3635 & 0.2759 \\
20,000 & 0.6341 & 2.4173 & 0.2711 \\
25,000 & 0.6218 & 2.6527 & 0.2551 \\
30,000 & 0.6144 & 2.8449 & 0.2459
\end{tabular}


The intensity of economic and ecological civilization is:

$$
U_{3}=\phi_{2}(x, y, z, w, S, t) / \phi_{3}(x, y, z, w, V, t)
$$

\section{SYSTEM PHASE DIAGRAM AND PARAMETER DETERMINATION}

To determine the model's coefficients accurately, data collected from the statistical yearbooks of Fuyang City and Anhui Province were utilized (see Table 1).

Fuyang's natural gas consumption was analyzed using regression analysis (see Table 2).

Regression analysis shows that the fit is best when consumption reaches 110 million cubic meters, so we select $M=1.1$.

Given the investments made in Fuyang's natural gas infrastructure from 2007 to 2016 (Table 3), the coefficient of Fuyang's total natural gas investment was obtained by fitting the data curve: the error is less than $10^{-5}$, and the result is $c_{2}=0.0089$.

From Hao et al. (2019) we know that $c_{1}=0.00416$ has a parameter value $k_{1}$. The econometric regression and empirical analysis of the development of ecological civilization and the evolution of energy consumption in the major developed countries in the world indicate that the growth rate of energy consumption in a developed country has an elastic impact on the growth rate of ecological civilization. In particular, there is evidence that this elasticity coefficient is 0.006 . In other words, a unit of growth in the energy consumption level results in 0.006 units of growth in the ecological civilization construction level. The meaning of parameters $k_{2}$ and $c_{3}$ is mutual influence and dialectical unity of interaction. Thus, their values are the same.

TABLE 3 | Overview of natural gas investment in Fuyang City from 2007 to 2016.

\begin{tabular}{ccc}
\hline Year & GDP in Fuyang (10 $\mathbf{4}$ yuan) & Natural gas investment (10 $\mathbf{4}^{\mathbf{y u a n})}$ \\
\hline 2007 & $1,130,000$ & $13,791.66$ \\
2008 & $1,125,000$ & $24,106.33$ \\
2009 & $1,128,000$ & $24,016.66$ \\
2010 & $7,215,298$ & $50,961.33$ \\
2011 & $8,532,068$ & 33,440 \\
2012 & $9,625,290$ & $35,501.66$ \\
2013 & $10,997,133$ & 39,102 \\
2014 & $11,889,663$ & 72,424 \\
2015 & $12,674,500$ & 99,332 \\
2016 & $14,019,000$ & $240,884.33$ \\
\hline
\end{tabular}

The statistical yearbooks of Fuyang City provide the economic value and ecological civilization construction fund value of Fuyang City over the last 10 years. We obtained $k_{2}=c_{3}=0.776$ by curve-fitting, and the other parameters were optimized by the neural network model. The results are shown in Table 4.

Taking the data of Fuyang City in 2000 as the initial value $(0.0034,0.19,2.0,0.0012)$, and using numerical simulations, it can be seen from Figure $\mathbf{1}$ that the system is stable.

As shown in Figure 2, the development value of ecological civilization in Fuyang City is about 0.005125 , which is much lower than that in developed cities such as Paris (0.02115) and Seoul (0.01323) (Zhu, 2016). This reflects the fact that there have been some initial achievements in Fuyang's ecological civilization construction in recent years, but that there is still quite a ways to go. At present, natural gas accounts for a very low proportion of energy consumption at less than $10 \%$ of total energy consumption. Thus, it can be inferred that the development value of ecological civilization of the disposable energy is about 0.05125 , which is close to the national average of 0.054043 (Zhu, 2016). The use of the various clean and sustainable forms of energy must be increased while coal consumption is steadily reduced.

It can be seen from Figure 3 that the natural gas energy intensity is smaller and fluctuates less than does the construction of ecological civilization. However, following the introduction of the concept of construction of ecological civilization to the people of Fuyang, and the strengthening of the relevant institutions and the cultivation of awareness, the intensity of natural gas energy in the city began to decline. The red line in the chart shows that, over time, the intensity of natural gas energy has fluctuated very little and decreased gradually.

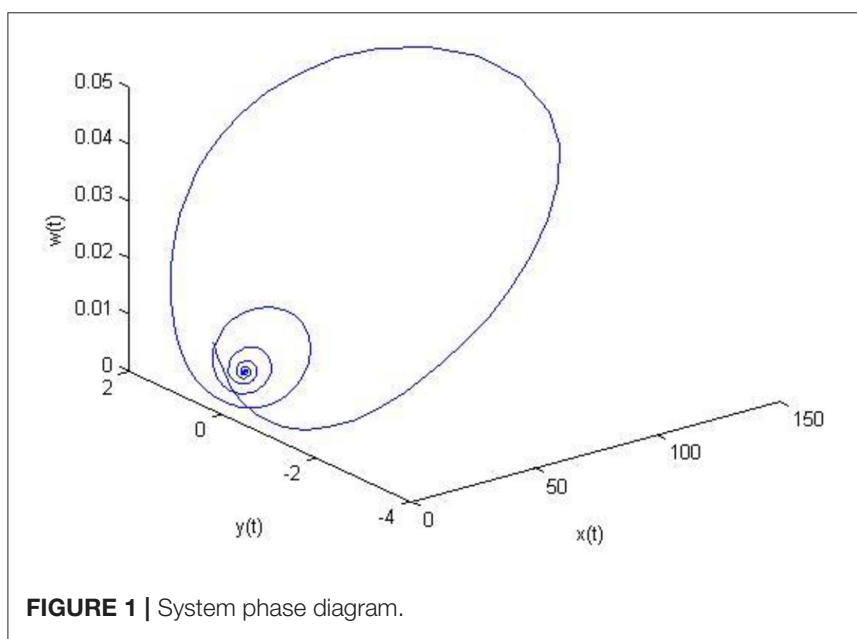

TABLE 4 | System coefficients after model optimization.

\begin{tabular}{lccccccccc}
\hline$a_{1}$ & $a_{2}$ & $a_{3}$ & $a_{4}$ & $a_{5}$ & $b_{1}$ & $b_{2}$ & $b_{3}$ & $c_{1}$ & $c_{2}$ \\
0.028 & 0.961 & 0.055 & 1.87 & 16.7 & 0.316 & 0.205 & 0.15 & 0.00416 & 0.0089 \\
$c_{3}$ & $M$ & $N$ & $L$ & $K$ & $Q$ & $k_{1}$ & $k_{2}$ & $H$ \\
0.0776 & 1.1 & 0.13 & 0.11 & 28 & 7.7 & 0.006 & 0.0776 & 0.018
\end{tabular}




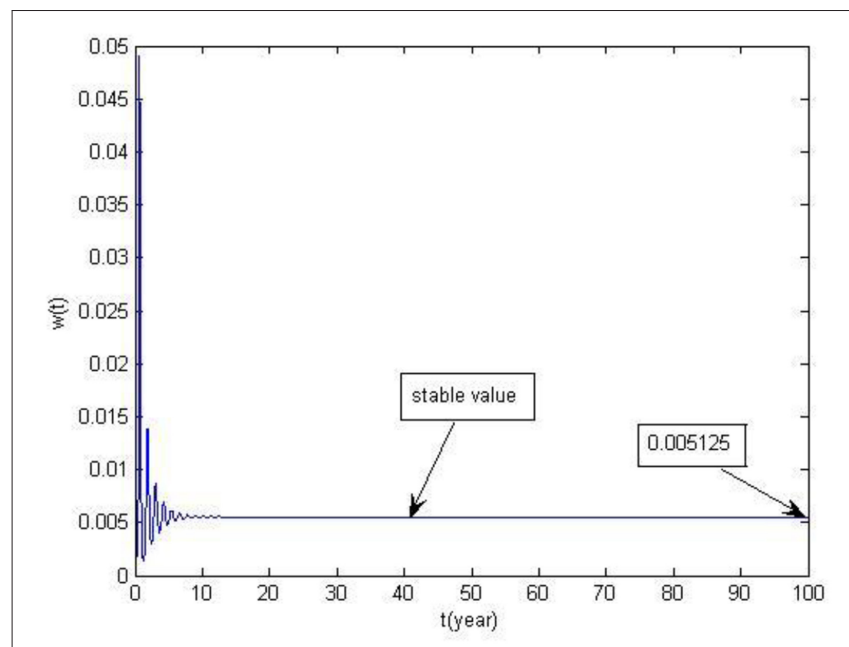

FIGURE 2 | Simulation value of variable ecological civilization.

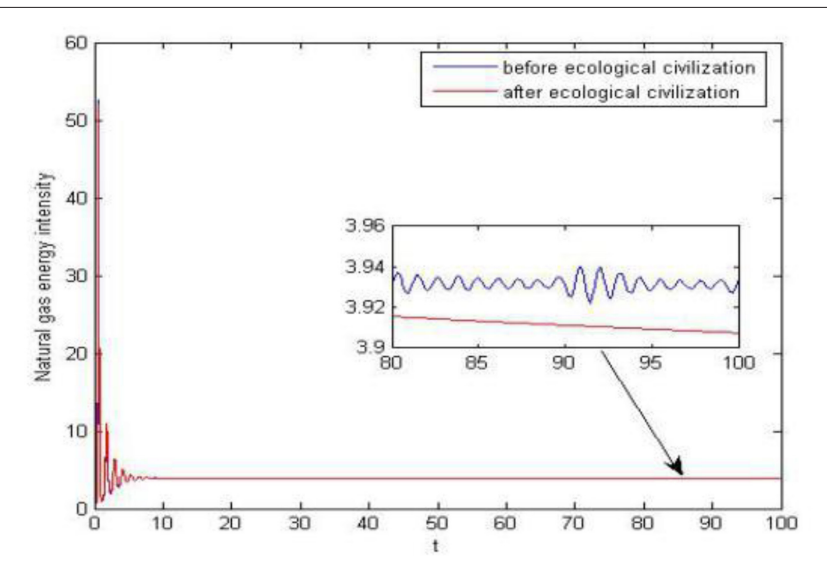

FIGURE 3 | Comparison of natural gas energy intensity.

In December 2017, Fuyang City was issued with (trial) detailed rules for the investigation of leading cadres of the Party and Government of Anhui Province who have caused ecological environmental damage. The municipal government attaches great importance to this. It studied and communicated the rules, formulated implementation measures, and planned and implemented measures focused on the prevention and control of air, water, and soil pollution. It also collated the feedback gathered by the environmental protection inspectors and imposed serious discipline and accountability measures to rectify the environmental problems. As its next steps, the government should implement its policies vigorously, increase accountability in the field of ecological environmental protection, improve long-term regulatory mechanisms, and continue its efforts to promote the construction of ecological civilization and environmental protection. It should also advocate less materialistic lifestyles in favor of healthier ones, and foster green and low carbon mainstream values. The intensity of natural gas energy use in Fuyang City

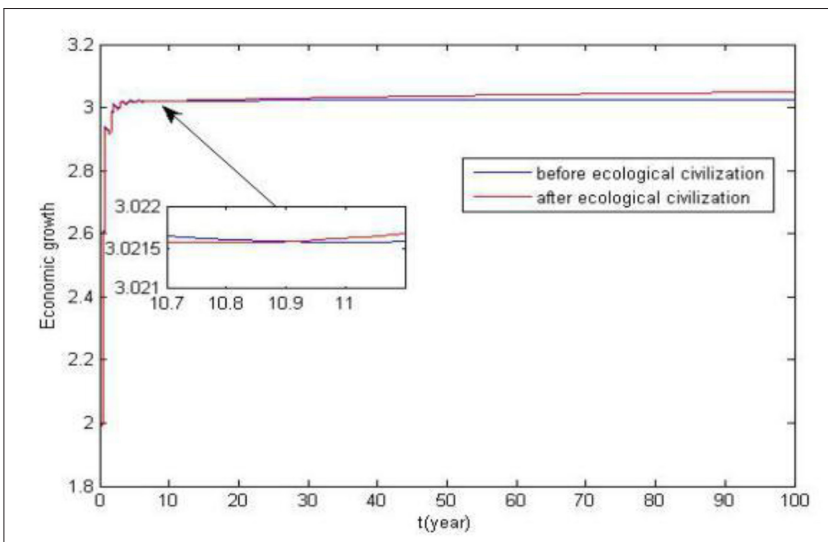

FIGURE 4 | Comparison of economic growth.

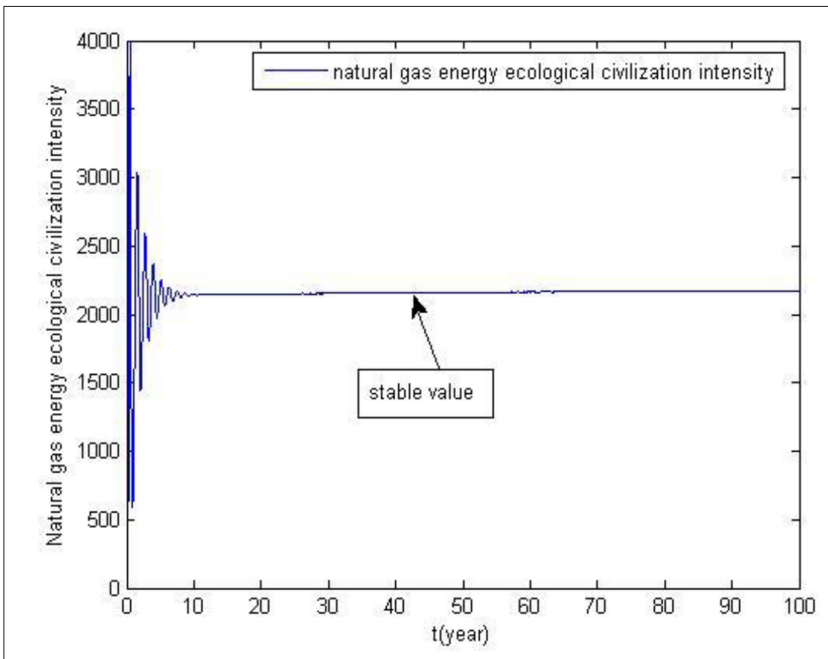

FIGURE 5 | Natural gas energy ecological civilization ecological construction intensity chart.

has gradually begun to decline. In the longer term, the implementation of ecological civilization will promote economic growth (Figure 4).

The intensity of natural gas energy is about 2,160,000 cubic meters/10,000 yuan (Figure 5). At present, there is almost no renewable energy utilization in Fuyang City. This demonstrates that the ecological civilization construction requires a great deal of effort. Switching from coal to natural gas is not enough alone; the use of renewable green energy sources is also required (Zhang et al., 2018). In 2017, the proportion of natural gas in total energy consumption in Fuyang City was only $6.41 \%$, which was lower than the national average level. Hence, there is still much room for improvement in ecological civilization construction.

It can be seen from Figure 6 that future economic and ecological civilization of Fuyang City is stable at 541 . Drawing on the calculation method of Shanghai's ecological civilization with land use as the research object (Shi and 


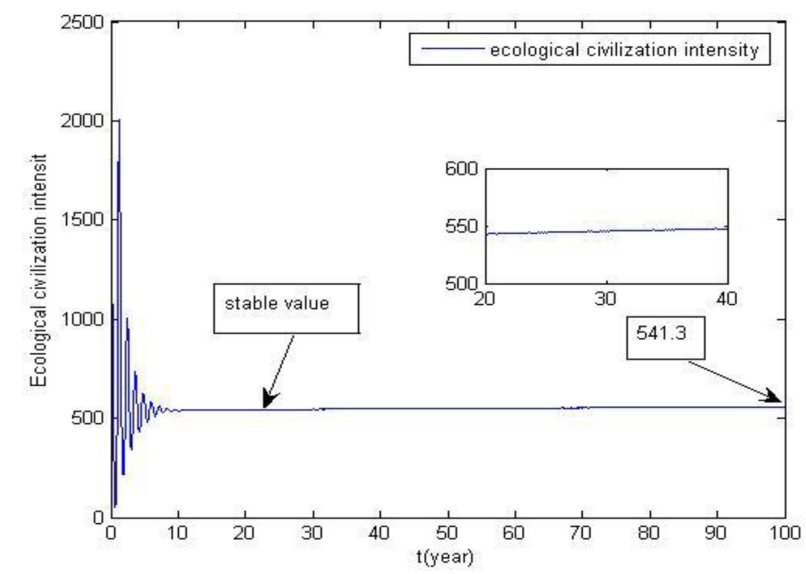

FIGURE 6 | Chart of the intensity of economic and ecological construction progress.
Sun, 2017), the urban area of Fuyang City is $200 \mathrm{~km}^{2}$, with an average annual expenditure of 1.32 million yuan and an intensity of 660 ten thousand yuan $/ \mathrm{km}^{2}$, reflecting the fact that Fuyang City has matured after implementation of the ecological civilization system. The strength of the economic and ecological civilization is stable at a value of 541. It is also very likely to serve as a reference for future ecological civilization investment.

\section{PROMOTION OF THE HEALTHY DEVELOPMENT OF URBAN ENERGY ECOLOGICAL CIVILIZATION CONSTRUCTION}

To meet the increasingly stiff environmental requirements stipulated by the local and central governments, all cities are actively upgrading their energy structures. The use of natural gas is gradually penetrating all of the urban energy systems. Government regulation and control in the early stages of natural gas development is required, through strategies for adjustment, regulation, and control of the natural gas market. The goal is to achieve a healthy, sustainable, and stable development strategy for the natural gas market, improve its structure, and promote balanced social development. In the next section, we identify and analyze several effective regulatory strategies to stabilize China's natural gas market.

\section{STRATEGY 1: DEEPEN THE NATURAL GAS MARKET REFORMS AND VIGOROUSLY ADVOCATE THE DEVELOPMENT OF NATURAL GAS}

In China, especially in third-tier cities such as Fuyang, the proportion of natural gas consumption in total energy

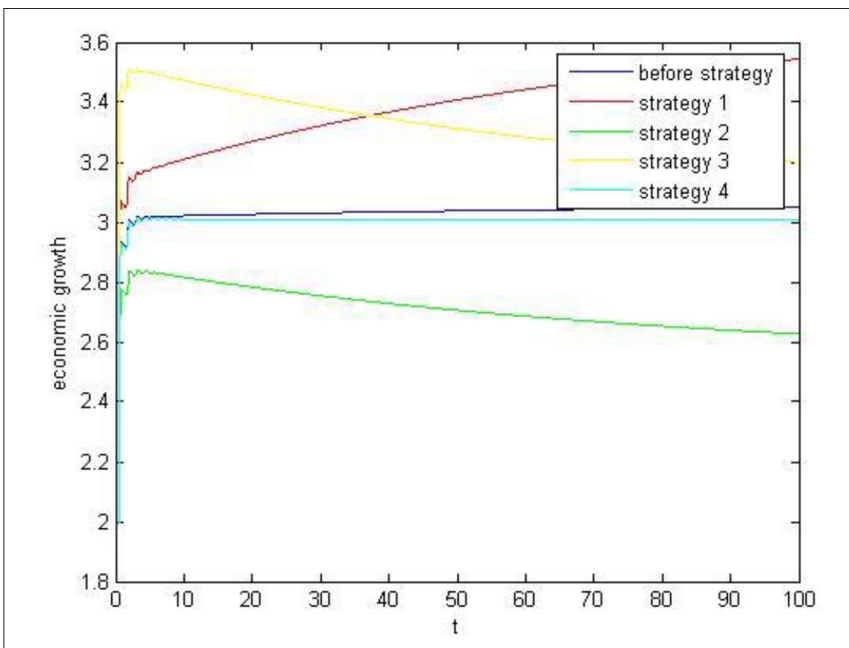

FIGURE 7 | Economic growth strategy chart.

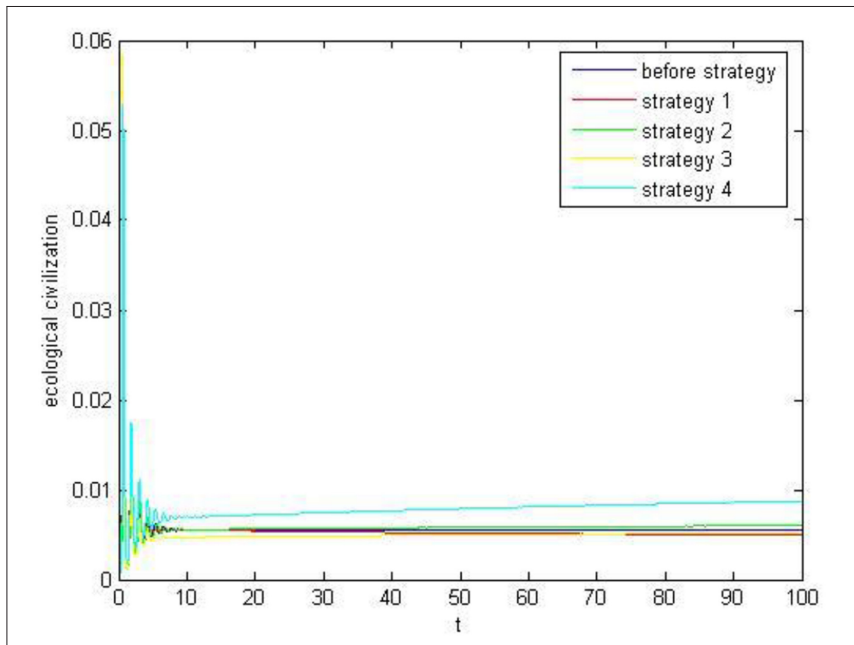

FIGURE 8 | Strategy map of ecological civilization variables.

consumption is not large. To build clean and environmentally friendly cities, China must increase the proportion of natural gas in its urban energy systems as quickly as possible, deepen the relevant market reforms, and increase imports of natural gas. These actions will increase the system model coefficient $a_{1}$. To avoid excessive wastage of natural gas and control the increase of coefficient $a_{1}$, it is necessary to not only increase natural gas consumption but also ensure price stability. Price increases should be restrained in order to increase coefficient $K$ and also increase natural gas consumption, resulting in economic growth. When $a_{1}$ increases from 0.028 to 0.048 and $K$ increases from 28 to 30, other parameters remain unchanged, as shown in Figures 7-11, for economic growth, ecological civilization construction, natural gas energy ecological civilization intensity, economic ecological civilization intensity, and natural gas energy intensity. 


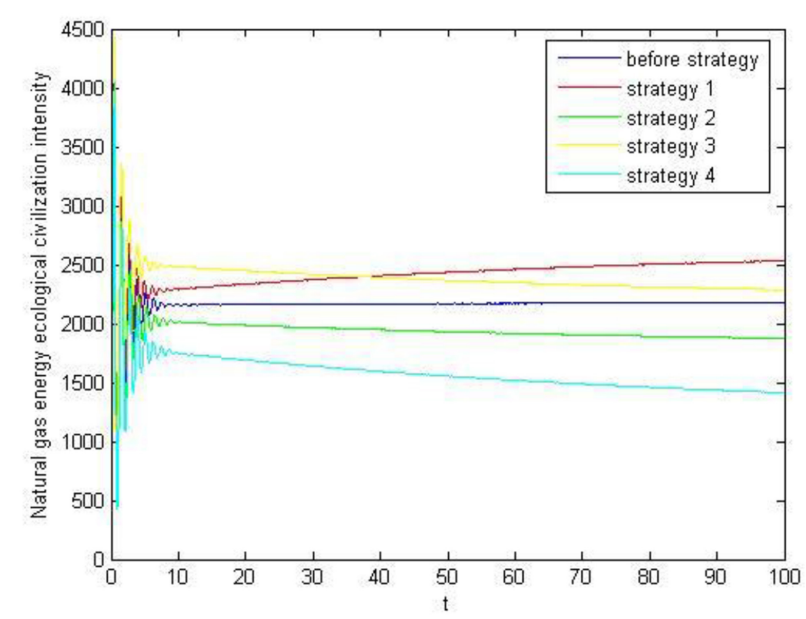

FIGURE 9 | Intensity of natural gas energy.

\section{STRATEGY 2: IMPLEMENT HIGH AND LOW PRICES}

The second recommended strategy is to implement gas peakvalley pricing and improve the step price mechanism. This can effectively avoid the peak load of natural gas consumption by gradually making demand stable. In terms of the model, the parameter $a_{4}$ would decrease. At the same time, these reforms can assist in reducing the influence of the natural gas price on consumption, so that model parameter $b_{3}$ would be reduced. When the system state $a_{4}$ is reduced from 1.87 to 1.77 , and when $b_{3}$ is reduced from 0.15 to 0.14 , other parameters remain unchanged (as above, see Figures 7-11).

\section{STRATEGY 3: TAKE APPROPRIATE ADMINISTRATIVE MEASURES}

Appropriate administrative measures should be taken to adjust the inherent growth rate parameter $b_{2}$ and the natural gas price peak value $L$. By loosening the price controls on natural gas, the government can ensure that the supply and consumption of natural gas in the natural gas market is balanced and that the price remains within a reasonably acceptable range for consumers. This will also promote the market allocation of resources and ensure economic growth and sustainable development. In terms of the model, the specific measures recommended are to adjust the price parameters $b_{2}$ and $L$. When parameter $b_{2}$ increases from 0.205 to 0.215 and parameter $L$ decreases from 0.11 to 0.10 , other parameters remain unchanged (as above, see Figures 7-11).

\section{STRATEGY 4: INDUSTRIAL STRUCTURE ADJUSTMENT}

An effective strategy to strengthen the scientific management of the natural gas energy system is to stabilize the natural gas

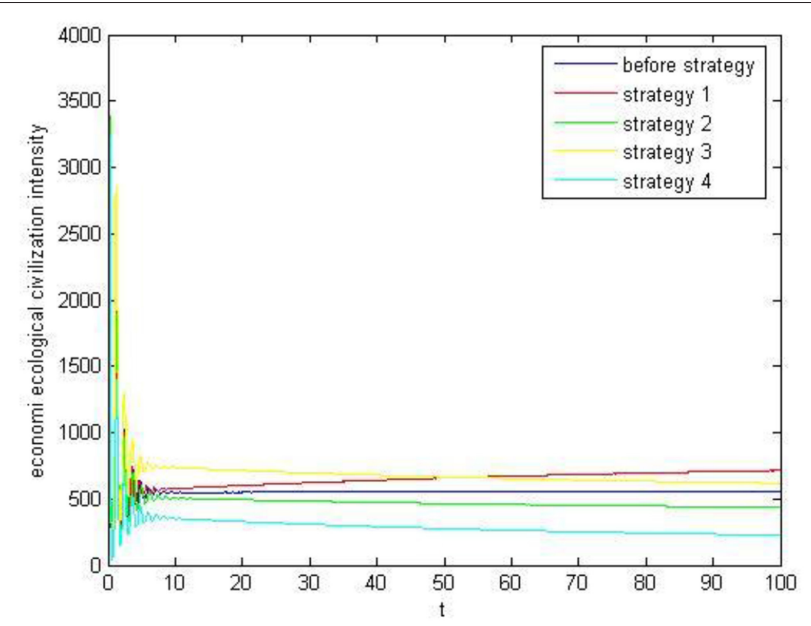

FIGURE 10 | Intensity of economic ecological civilization.

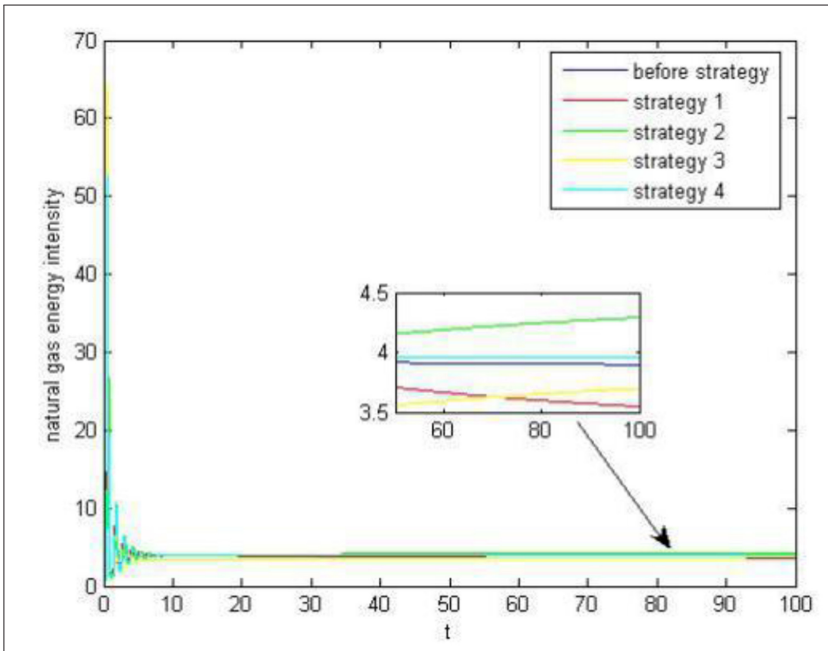

FIGURE 11 | Natural gas energy intensity diagram.

price. What is needed is a transformation from high natural gas consumption at low efficiency, to low consumption at high efficiency. Economic growth is restrained by reducing the economic growth coefficient $c_{1}$ and increasing the science and technology investment coefficient $c_{2}$ for natural gas development. When $c_{1}$ decreases from 0.00416 to 0.00406 and parameter $c_{2}$ increases from 0.0089 to 0.0093 , the other parameters remain unchanged (as above, see Figures 7-11).

As we know from Figure 4, the construction of ecological civilization will make economic growth decline in the short term, but thereafter the economy will grow smoothly. From Figure 7, we can see that among the four strategies, only Strategy 4 causes a short-term decline in economic growth (followed by resumption of smoother growth), in line with the results shown in Figure 4. In contrast, the other strategies result in economic growth declining and fluctuating greatly. 
From Figure 8, we can see that the construction of ecological civilization is further enhanced under Strategies 2 and 4. Strategy 2 aligns with the state policy to liberalize the price of the competitive link. The way for the state to liberalize the price of the competitive link is to take appropriate measures to liberalize the price of natural gas, implement peak and valley prices for natural gas, perfect the ladder price mechanism, and guide the rationalization of natural gas consumption. The government should establish a natural gas supervision system covering the whole industrial chain and the whole process, and strengthen government supervision over market access (Dou et al., 2013), trading behavior, monopoly links, prices and costs, quality, safety, environmental protection, and other key links. In addition, it should hasten the improvement of the natural gas industry standardization system and undertake other administrative measures. The adjustment of the industrial structure is a fundamental condition for realizing the stable and sustainable development of China's economy (Shen and Shi, 2018; Wang et al., 2019). It is the main way to create economic benefits by effectively promoting the transformation of the mode of economic growth. In addition, it is an important condition for reducing energy consumption and environmental pollution and improving the ecological environment. Blind pursuit of high economic growth is not conducive to promoting the adjustment of industrial structures; rather, it aggravates the imbalances in the industrial structures.

It can be seen from Figures 9, 10 that Strategy 4 minimizes the intensity of natural gas energy ecological civilization and economic ecological civilization, which are the best ways to achieve urban construction of ecological civilization at present. Figure 11 shows that Strategy 4 does not minimize natural gas energy intensity. Strategy 1 is the lowest, indicating that the construction of urban ecological civilization should be achieved with a combination of Strategies 1, 2, and 4, or other methods to supervise the construction of urban ecological civilization. According to the above analysis, to improve the development of Fuyang's natural gas energy and ecological civilization, and to actively deepen the reform of the natural gas market (Shi and Padinjare, 2017), the government should implement peak and valley real-time prices and ladder prices, vigorously develop the tertiary industry, and strengthen the industrial structure adjustments. To date, Fuyang City has implemented ladder prices for natural gas, but has not implemented real-time peak-valley prices. The value of the tertiary industry has increased year by year. The government of Fuyang is planning to implement real-time peak and valley prices for natural gas and hasten the development of the tertiary industry.

Urban ecological civilization construction is a systematic project requiring the government to consider the development of the economy and environmental optimization, and determine which are the relevant departments to integrate natural gas resources, undertake coordinated development planning, publicity and education, policies and measures, and pay attention to new energy factors (Li et al., 2018; Wang et al., 2018; Xu et al., 2019). In addition, to realize the rapid development of ecological civilization and sustainable development of cities, it is necessary to coordinate the construction of propaganda software and policy hardware.

\section{CONCLUSIONS}

This paper marks the first attempt ever made to quantify the construction of urban ecological civilization and promotes an urban natural gas production and consumption revolution from the perspective of ecological civilization. Ecological civilization is conducive to enhancing energy security and support capabilities, improving the quality and efficiency of economic development, strengthening urban sustainable development, and proactively responding to global climate change. Comprehensively promoting the construction of ecological civilization has important practical significance and far-reaching strategic significance for accelerating the construction of a modernized country. By adhering to the promotion of industrial restructuring, deepening the reform of the natural gas market, and liberalizing the natural gas price market mechanism, the government can promote a natural gas revolution as a national policy for building urban energy systems development, energy security, efficient energy consumption, supply diversification, and technological innovation. If Fuyang City and indeed all cities in China are to develop in a healthy and sustainable manner, the deepening of reforms and fundamental transformation of energy production and consumption patterns are imperative.

\section{DATA AVAILABILITY STATEMENT}

The datasets generated for this study are available on request to the corresponding author.

\section{AUTHOR CONTRIBUTIONS}

YH completed the simulations and experimental research, and wrote the manuscript. SL and QX completed the experimental research and revised the article.

\section{FUNDING}

This work was supported by the National Key Research and Development Program Sub-topic (2017YFC0804408), the National Natural Science Foundation of China (71573256), the Major Projects of National Social Science Foundation (16ZDA056), and the 2019 Anhui Province Humanities and Social Science Key Research Project (SK2019A0540). 


\section{REFERENCES}

Cheng, D., Shi, X., and Yu, J. (2019). How does the Chinese economy react to uncertainty in international crude oil prices?. Int. Rev. Econ. Finan. 64, 147-164. doi: 10.1016/j.iref.2019.05.008

Dou, X., Li, S., and Wang, J. (2013). Ecological strategy of city sustainable development. APCBEE Proc. 5, 429-434. doi: 10.1016/j.apcbee.2013.05.074

$\mathrm{Du}, \mathrm{X}$. (2015). Analysis of energy development and reform in China under the background of ecological civilization (in Chinese). Chinese Eng. Sci. 17, 46-53. doi: 10.3969/j.issn.1009-1742.2015.08.008

Emma, S., and John, S. (2013). Price discovery in European natural gas markets. Energy Policy 61, 628-634. doi: 10.1016/j.enpol.2013.06.080

Fang, G., Tian, L., and Fu, M. (2012). Analysis and application of a novel threedimensional energy-saving and emission- dynamic evolution system. Energy 40, 291-299. doi: 10.1016/j.energy.2012.01.071

Fang, G., Tian, L., and Fu, M. (2018b). How to promote the development of energysaving and emission-reduction with changing economic growth rated A case study of China. Energy 143, 732-745. doi: 10.1016/j.energy.2017.11.008

Fang, G., Tian, L., Fu, M., Sun, M., Du, R., Lu, L., et al. (2017). The effect of energy construction adjustment on the dynamical evolution of energysaving and emission-reduction system in China. Appl. Energy 196, 180-189. doi: 10.1016/j.apenergy.2016.11.049

Fang, G., Tian, L., Liu, M., Fu, M., and Sun, M. (2018a). How to optimize the development of carbon trading in China-Enlightenment from evolution rules of the EU carbon price. Appl. Energy 211, 1039-1049. doi: 10.1016/j.apenergy.2017.12.001

Fang, G., Tian, L., and Sun, M. (2013). The impacts of carbon tax on energy intensity and economic growth - A dynamic evolution analysis on the case of China. Appl. Energy 110, 17-28. doi: 10.1016/j.apenergy.2013.04.041

Hansen, M. H., Li, H., and Svarverud, R. (2018). Ecological civilization: interpreting the Chinese past, projecting the global future. Glob. Environ. Change 53, 195-203. doi: 10.1016/j.gloenvcha.2018.09.014

Hao, Y., Han, X., and Wang, M. (2019). Study on natural gas energy system model of fuyang city (in Chinese). Energy Energy Conserv. 4, 43-45. doi: 10.3969/j.issn.2095-0802.2019.04.021

He, Y., and Lin, B. (2017). The impact of natural gas price control in China: a computable general equilibrium approach. Energy Policy 107, 524-531. doi: 10.1016/j.enpol.2017.05.015

Ji, Q., Fan, Y., and Troilo, M. (2018). China's natural gas demand projections and supply capacity analysis in 2030. Energy J. 30, 53-70. doi: 10.5547/01956574.39.6.qji

Ji, Q., Geng, J., and Fan, Y. (2014). Separated influence of crude oil prices on regional natural gas import prices. Energy Policy 70, 96-105. doi: 10.1016/j.enpol.2014.03.019

Ji, Q., and Zhang, H. (2018). What drives natural gas prices in the United States? A directed acyllic graph approach. Energy Econ. 69, 79-88. doi: 10.1016/j.eneco.2017.11.002

Jiang, B., Bai, Y., and Wong, C. (2019). China’s ecological civilization program - Implementing ecological redline policy. Land Use Policy 81, 111-114. doi: 10.1016/j.landusepol.2018.10.031

Li, J., Zhang, D., and Su, B. (2019). The impact of social awareness and lifestyles on household carbon emissions in China. Ecol. Econ. 160, 145-155. doi: 10.1016/j.ecolecon.2019.02.020

Li, Z., Shao, S., and Shi, X. (2018). Structural transformation of manufacturing, natural resource dependence, and carbon emissions reduction: evidence of a threshold effect from China. J. Cleaner Prod. 206, 920-927. doi: 10.1016/j.jclepro.2018.09.241

Liu, G., Dong, X., Jiang, Q., Dong, C., and Lia, J. (2018). Natural gas consumption of urban households in China and corresponding T influencing factors. Energy Policy 122, 17-26. doi: 10.1016/j.enpol.2018.07.016

Mark, A., Peter, H., Kenneth, M. III., and Ted, T. (2017). Employment impacts of upstream oil and gas investment in the United States. Energy Econ. 62, 171-180. doi: 10.1016/j.eneco.2016.12.012

Shen, Y., and Shi, X. (2018). Risk transmission mechanism between energy markets: a VAR for VaR approach. Energy Econ. 75, 377-388. doi: 10.1016/j.eneco. 2018. 08.027

Shi, X., and Padinjare, H. M. (2017). Global impact of uncertainties in China's gas market. Energy Policy 104, 382-394. doi: 10.1016/j.enpol.2017.02.015
Shi, X., and Sun, S. (2017). Energy price, regulatory price distortion and economic growth: a case study of China. Energy Econ. 63, 261-271. doi: 10.1016/j.eneco.2017.02.006

Shia, Y., and Shi, S. (2019). Relationship between social civilization forms and carbon emission intensity: a study of the Shanghai metropolitan area. J. Cleaner Prod. 228, 1552-1563. doi: 10.1016/j.jclepro.2019. 04.356

Tanaka, S. (2015). Environmental regulations on air pollution in China and their impact on infant mortality. J. Health Econ. 42, 90-103. doi: 10.1016/j.jhealeco.2015.02.004

van Ruijven, B., and van Vuuren, D. P. (2009). Oil and natural gas prices and greenhouse gas emission mitigation. Energy Policy 37, 4797-4808. doi: 10.1016/ j.enpol.2009.06.037

Wang, H., Fang, H., Yu, X., and Wang, K. (2015). Development of natural gas vehicles in China: an assessment of enabling factors and barriers. Energy Policy 85, 80-93. doi: 10.1016/j.enpol.2015.05.012

Wang, K., Wu, M., Sun, Y., and Shi, X. (2019). Resource abundance, industrial structure, and regional carbon emissions efficiency in China. Resour. Policy 60, 203-214. doi: 10.1016/j.resourpol.2019.01.001

Wang, L., and Gao, J. (2017). China's road to ecological civilization (in Chinese). Wisdom China 14, 4-5. doi: 10.3969/j.issn.1009-5349.2017.18.119

Wang, Q., Su, B., and Zhou, P. (2018). Contributions to sector-level carbon intensity change: an integrated decomposition analysis. Energy Econ. 70, 12-25. doi: 10.1016/j.eneco.2017.12.014

Xiao, J. (2008). Ecological energy construction in ecological civilization construction (in Chinese). J. Beijing Petrol. Manage. Cadre Inst. 1, 4-9. doi: 10.3969/j.issn.1008-4576.2008.01.001

Xie, L., Flynn, A., May, T. M., and Ali, C. (2019). The making and remaking of ecological space in China: the political ecology of Chongming Eco-Island. Polit. Geogr. 69, 89-102. doi: 10.1016/j.polgeo.2018.12.012

$\mathrm{Xu}, \mathrm{B}$., and Lin, B. (2019). Can expanding natural gas consumption reduce China's $\mathrm{CO}_{2}$ emissions? Energy Econ. 81, 393-407. doi: 10.1016/j.eneco.2019.04.012

$\mathrm{Xu}, \mathrm{X}$., Wei, Z., and Ji, Q. (2019). Global renewable energy development: influencing factors trend predictions and countermeasures. Resour. Policy 63, 1-15. doi: 10.1016/ j.resourpol.2019.101470

Yu, Y. (2018). Environmental catching-up, eco-innovation, and technological leadership in China's pilot ecological civilization zones (in Chinese). Technological 7, 32-37.

Zeng, J., and Liang, Q. (2018). Research and enlightenment on ecological civilization and energy consumption evolution of major developed countries in the world (in Chinese). J. Econ. Res. 36, 25-127.

Zhang, L., and Yang, J. (2019). Evaluation of the ecological civilization index of China based on the bouble benchmark progressive method. J. Cleaner Prod. 222, 511-519. doi: 10.1016/j.jclepro.2019.02.173

Zhang, M., Liu, Y., and Wu, J. (2018). Index system of urban resource and environment carrying capacity based on ecological civilization. Environ. Impact Assess. Rev. 68, 90-97. doi: 10.1016/j.eiar.2017.11.002

Zhang, W., and Tian, L. (2016). The evolution model of electricity market on the stable development in China and its dynamic analysis. Energy 114, 344-359. doi: 10.1016/j.energy.2016.08.015

Zhou, B., Zhang, C., and Wang, Q. (2018). How does emission trading reduce China's carbon intensity? An exploration using a decomposition and difference-in-differences approach. Sci. Total Environ. 676, 514-523. doi: 10.1016/j. scitotenv.2019.04.303

Zhu, Z. (2016). Assessment of the Impact of Energy Utilization on Ecological Civilization in Major Developed Countries and Its Implications for China (in Chinese). Nanjing: East China Institute of Technology.

Conflict of Interest: The authors declare that the research was conducted in the absence of any commercial or financial relationships that could be construed as a potential conflict of interest.

Copyright (c) $2020 \mathrm{Hao}$, Li and Xia. This is an open-access article distributed under the terms of the Creative Commons Attribution License (CC BY). The use, distribution or reproduction in other forums is permitted, provided the original author(s) and the copyright owner(s) are credited and that the original publication in this journal is cited, in accordance with accepted academic practice. No use, distribution or reproduction is permitted which does not comply with these terms. 